ИЗВЕСТИЯ АКАДЕМИИ НАУК ЭСТОНСКОИ ССР. ТОМ 29 ХИМИЯ. 1980, № 2

\title{
ОКИСЛИТЕЛЬНЫЕ ПРЕВРАЩЕНИЯ ДВУХАТОМНЫХ ФЕНОЛОВ В ВОДНОЙ СРЕДЕ
}

В общем загрязнении гидросферы, достигшем в настоящее время высокого уровня, значительную часть составляют фенольные загрязнения. В процессах самоочищения водной среды от фенольных соединений как под действием физико-химических, так и биологических факторов преобладающую роль играют окислительные превращения [1,2]. Особенности окисления фенолов весьма полно изучены для концентрированных растворов и при сравнительно жестких условиях (повышенные температура и давление, сильнощелочная среда), но недостаточно выявлены для специфических условий самоочищения природных вод. Между тем известно, что при окислении фенолов возможно формирование промежуточных продуктов, еще более токсичных, нежели исходный загрязнитель $\left[{ }^{3,4}\right]$.

Соответственно в настоящей работе основным объектом исследования явилась кинетическая характеристика процессов окисления фенолов при низких концентрациях в водной среде во взаимодействии с молекулярным кислородом в неактивированной (автоокисление) и фотоинициируемой системах, отвечающих условиям их естественной деградации. Полученные при этом данные смогут явиться основой для приближенного расчета и, возможно, моделирования процессов самоочищения природных вод.

\section{Объекты и методика исследования}

На данном этапе исследования основными объектами явились наиболее типичные представители «сланцевых» двухатомных фенолов - резорцин (Р) и 5-метилрезорцин (5MP) - основные загрязнители вод в сланцевой промышленности. Для решения поставленной выше задачи применительно к этим модельным соединениям представляется возможным и достаточным получение макрокинетических показателей, основанных на определении убыли исходной концентрации фенолов во времени. Известно, что продукты окисления $\mathrm{P}$ и его производных в концентрированных смесях имеют сложный состав и часто близкую к исходному фенолу структуру [5], что затрудняет определение $\mathrm{P}$ и его производных в реакционной смеси простыми аналитическими методами. Осуществление поставленной задачи потребовало применения специальной методики анализа, исключающей искажающее влияние продуктов реакции (димеров, полимеров, продуктов гидроксилирования) на определение убыли содержания исходного вещества.

Выбранная нами методика [] ${ }^{6}$ была несколько изменена применительно к условиям кинетического эксперимента. Пробу из реактора (водный раствор при концентрации Р и $5 \mathrm{MP}$ порядка $18 \cdot 10^{-5} \mathrm{M}$ или эфирный экстракт при более низких концентрациях) 
наносили на стеклянную пластинку с незакрепленным тонким слоем силикагеля $(40 / 100 \mu$, Chemapol, ЧССР). В качестве подвижной фазы использовали смесь бензола и диоксана в соотношении 4:1 по объему. Хроматографировали в стандартных условиях по восходящему методу. Идентификацию местоположения Р и $5 \mathrm{MP}$ на пластинке проводили по индексу удерживания: $R_{f}=0,40$ (P); $R_{f}=0,35$ (5MP). Адсорбционную зону, содержащую $\mathrm{P}$ или 5MP, шириной 25-30 мм отсасывали с помощью водоструйного насоса и пористого фильтра и десорбировали 3-4 порциями воды так, чтобы общий объем фильтрата составил ровно $10 \mathrm{~m}$. Далее к фильтрату прибавляли последовательно 2 капли 2\%-ного водного раствора 4-аминоантипирина, 6 капель 2 н. водного раствора аммиака и 4 капли $2 \%$-ного водного раствора $\mathrm{K}_{3} \mathrm{Fe}(\mathrm{CN})_{6}$. Тотчас же измерялась оптическая плотность раствора в кювете с толщиной слоя 20 мм на фотоколориметре ФЭК-56 М $(\lambda=490$ нм). Раствором сравнения служила дистиллированная вода, к которой были прибавлены все перечисленные выше реактивы.

Выбор уровня концентрации фенолов и параметров ведения изучаемого процесса определялся стремлением максимально приблизить условия эксперимента к реальному процессу самоочищения природных вод от фенольных соединений. Соответственно концентрация их в водном растворе варьировалась в пределах от 1 до 20 мг/ $\Omega$, температура - от 5 до $40^{\circ} \mathrm{C}$. В качестве реакционной среды в эксперименте использовалась бидистиллированная вода (для исключения влияния бактериального эффекта) и модельная вода Балтийского моря соленостью 7,22 [7] при pH 8,40. Опыты по автоокислению проводились в термостатированных стеклянных конических колбах емкостью $2 \Omega$, окислителем служил кислород воздуха, непрерывно подаваемый в реактор.

Кинетика фотоинициированного процесса изучалась в термостатированном реакторе емкостью 100 мл при облучении ртутно-кварцевой лампой СВД-120А. Эксперименты проводились при $20^{\circ}$, использовании кислорода воздуха в качестве окислителя и интенсивности облучения $10^{16} \kappa в а н т / м л \cdot c$, определенной феррооксалатной актинометрией. Предварительно в специальной серии опытов нами было установлено, что влияние температурного фактора в интервале $5-40^{\circ}$ на фотоинициированный процесс незначительно.

\section{Результаты эксперимента и их обсуждение}

Для обработки результатов был выбран дифференциальный метод расчета порядка реакции и константы скорости [ $\left.{ }^{8}\right]$. Скорость реакции в зависимости от концентрации выражается уравнением

$$
V=K \cdot C^{n_{0}},
$$

где $K$ - константа скорости, а $n_{c}-$ концентрационный порядок реакции. Логарифмирование выражения (1) дает

$$
\lg V=\lg K+n_{c} \lg C \text {. }
$$

Таким образом, зависимость логарифма скорости от логарифма концентрации - прямая линия. Расчет уравнений этих прямых проводился по методу наименьших квадратов [ [9].

На основании данных об изменении концентрации фенолов во времени определены концентрационный порядок и константа скорости (табл. 1) для процесса автоокисления. При расчете за начальную скорость принята средняя скорость в промежутке между начальной (нулевой) и непосредственно следующей за ней точкой контроля. Процесс окисления $\mathrm{P}$ и $5 \mathrm{MP}$ кислородом воздуха при всех температурах в зависимости от начальной концентрации описывается уравнением, где концентрационный порядок $n_{c}$ остается практически неизменным, рав- 
Таблица 1

Расчетные кинетические данные автоокисления резорцина и 5-метилрезорцина в бидистиллированной воде

\begin{tabular}{|c|c|c|c|c|c|c|}
\hline Вещество & $\begin{array}{l}\text { Teм } \\
\text { тур }\end{array}$ & $\begin{array}{l}\text { nпера- } \\
\mathrm{pa},{ }^{\circ} \mathrm{C}\end{array}$ & $\begin{array}{c}\text { Исходная } \\
\text { концентра- } \\
\text { ция C } \\
10^{-5} \mathrm{M}\end{array}$ & $\begin{array}{c}\text { Начальная } \\
\text { скорость } V \text {, } \\
10^{-8} M / 4\end{array}$ & $\begin{array}{c}\text { Концентрационный } \\
\text { порядок, } n_{c}\end{array}$ & $\begin{array}{l}\text { Константа } \\
\text { скорости, } K\end{array}$ \\
\hline P & & 40 & $\begin{array}{c}18,3 \\
4,58 \\
0,92\end{array}$ & $\begin{array}{r}88,0 \\
26,6 \\
9,2\end{array}$ & $0,74 \pm 0,042$ & $9,64 \pm 0,78$ \\
\hline $5 \mathrm{MP}$ & & 40 & $\begin{array}{c}18,0 \\
4,50 \\
0,90\end{array}$ & $\begin{array}{r}104,0 \\
41,4 \\
12,0\end{array}$ & $0,72 \pm 0,031$ & $13,2 \pm 0,82$ \\
\hline P & & 25 & $\begin{array}{c}18,2 \\
4,55 \\
0,91\end{array}$ & $\begin{array}{r}36,0 \\
14,6 \\
4,4\end{array}$ & $0,70 \pm 0,017$ & $4,80 \pm 0,19$ \\
\hline $5 \mathrm{MP}$ & & 25 & $\begin{array}{l}18,1 \\
4,52 \\
0,91\end{array}$ & $\begin{array}{r}52,0 \\
16,4 \\
6,8\end{array}$ & $0,69 \pm 0,057$ & $6,61 \pm 0,75$ \\
\hline $\mathrm{P}$ & & 15 & $\begin{array}{c}18,4 \\
4,60 \\
0,92\end{array}$ & $\begin{array}{r}22,0 \\
8,8 \\
2,8\end{array}$ & $0,70 \pm 0,033$ & $3,08 \pm 0,19$ \\
\hline $5 \mathrm{MP}$ & & 15 & $\begin{array}{c}18,3 \\
4,58 \\
0,92\end{array}$ & $\begin{array}{r}32,0 \\
11,0 \\
3,2\end{array}$ & $0,73 \pm 0,040$ & $3,80 \pm 0,35$ \\
\hline $\mathrm{P}$ & & 5 & $\begin{array}{c}18,4 \\
4,60 \\
0,92\end{array}$ & $\begin{array}{r}16,0 \\
6,2 \\
1,8\end{array}$ & $0,72 \pm 0,019$ & $2,00 \pm 0,08$ \\
\hline $5 \mathrm{MP}$ & & 5 & $\begin{array}{c}18,3 \\
4,58 \\
0,92\end{array}$ & $\begin{array}{r}20,0 \\
8,2 \\
2,2\end{array}$ & $0,72 \pm 0,046$ & $2,63 \pm 0,24$ \\
\hline
\end{tabular}

ным 0,70 (пределы колебаний $0,69-0,74)$. Константа скорости возрастает с повышением температуры.

Кинетические кривые показывают (рис. 1), что в процессе автоокисления происходит снижение скорости превращения фенолов во времени, но на начальной стадии процесса при относительно более низких температурах она остается почти постоянной. Установлено также, что автоокисление 5MP проис. ходит на $20-30 \%$ (в за. висимости от температуры) быстрее, чем Р в аналогичных условиях.

Рис. 1. Кинетические кривые окисления 5-метилрезорцина кислородом воздуха в бидистиллированной воде при исходной концентрации $18 \cdot 10^{-5} \mathrm{M}$ и температуре: $1-5^{\circ} \mathrm{C}, 2-15^{\circ}, 3-$ $25^{\circ}, 4-40^{\circ}$.

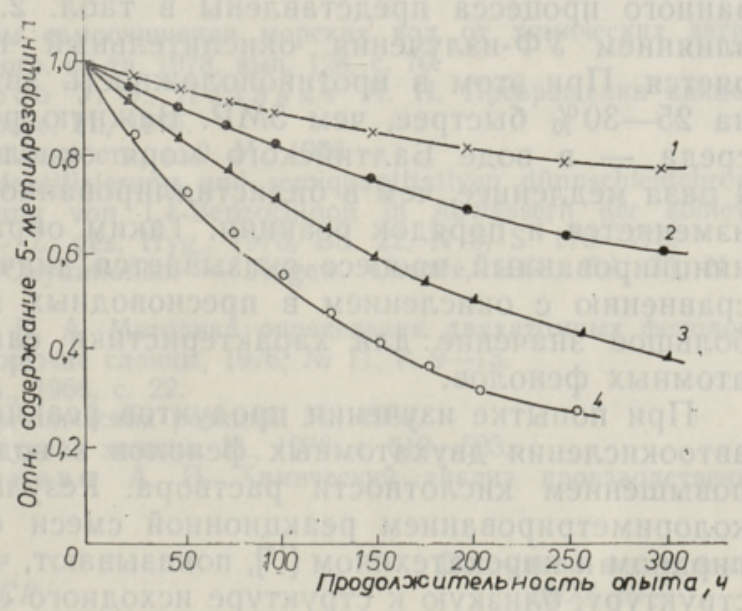


Таблица 2

Расчетные кинетические данные фотоинициированного окисления резорцина и 5-метилрезорцина при $20^{\circ} \mathrm{C}$ и интенсивности облучения $10^{16}$ квант/мл.c

\begin{tabular}{|c|c|c|c|c|c|}
\hline $\begin{array}{c}\text { Исход- } \\
\text { ное } \\
\text { веще- } \\
\text { ство }\end{array}$ & Среда & $\begin{array}{c}\text { Исходная } \\
\text { концентра- } \\
\text { ция } C, \\
10^{-5} M\end{array}$ & $\begin{array}{c}\text { Начальная } \\
\text { скорость } \\
V, 10^{-8} \mathrm{M} / 4\end{array}$ & $\begin{array}{c}\text { Концентрацион- } \\
\text { ный порядок, } \\
n_{c}\end{array}$ & $\begin{array}{c}\text { Константа } \\
\text { скорости, } \\
\text { K }\end{array}$ \\
\hline $\mathrm{P}$ & Бидистиллированная вода & $\begin{array}{c}18,9 \\
4,71 \\
0,91\end{array}$ & $\begin{array}{r}82500 \\
22400 \\
6300\end{array}$ & $0,84 \pm 0,033$ & $6570 \pm 420$ \\
\hline $5 M P$ &,- & $\begin{array}{l}18,7 \\
4,71 \\
0,94\end{array}$ & $\begin{array}{r}37400 \\
14300 \\
4800\end{array}$ & $0,68 \pm 0,008$ & $5000 \pm 69$ \\
\hline$P$ & $\begin{array}{l}\text { Модель воды Балтийско- } \\
\text { го моря }\end{array}$ & $\begin{array}{c}18,9 \\
4,61 \\
0,92\end{array}$ & $\begin{array}{r}18000 \\
6400 \\
1800\end{array}$ & $0,75 \pm 0,015$ & $1990 \pm 61$ \\
\hline $5 M P$ &,-- & $\begin{array}{c}18,7 \\
4,71 \\
0,94\end{array}$ & $\begin{array}{l}8400 \\
3300 \\
1400\end{array}$ & $0,57 \pm 0,045$ & $1400 \pm 120$ \\
\hline
\end{tabular}

На основе полученных данных по уравнению Аррениуса определена величина кажущейся энергии активации реакции автоокисления, которая составляет 7,45 и 6,83 ккал/моль для $5 \mathrm{MP}$ и Р соответственно. Таким образом, повышение температуры в пределах $5-40^{\circ}$ значительно стимулирует окисление фенолов.

При изучении влияния реакционной среды на кинетику процесса обнаружено, что при автоокислении изучаемых фенолов в бидистиллированной воде и на модели воды Балтийского моря кинетические кривые совпадают в пределах ошибки опыта. Таким образом, наличие в реакционной смеси минеральных солей, по составу отвечающих воде Балтийского моря, на кинетику автоокисления не оказывает влияния.

Как уже указывалось выше, наряду с неактивированным взаимодействием с молекулярным кислородом, одним из важных элементов суммарного процесса самоочищения вод является окисление фенолов, инициированное солнечным светом, в частности излучением ультрафиолетовой области. Полученные кинетические показатели фотоинициированного процесса представлены в табл. 2. Они показывают, что под влиянием УФ-излучения окислительный процесс существенно ускоряется. При этом в противоположность автоокислению Р деградирует на 25-30\% быстрее, чем 5MP. Важную роль в этом процессе играет среда - в воде Балтийского моря окисление протекает примерно в 4 раза медленнее, чем в бидистиллированной воде. С изменением среды изменяется и порядок реакции. Таким образом, в морской воде фотоинициированный процесс оказывается значительно заторможенным по сравнению с окислением в пресноводных водоемах. Этот факт имеет большое значение для характеристики самоочищения моря от двухатомных фенолов.

При попытке изучения продуктов реакции установлено, что процесс автоокисления двухатомных фенолов в водной среде сопровождается повышением кислотности раствора. Результаты, полученные прямым колориметрированием реакционной смеси (см. рис. 2) с 4-аминоантипирином и пирокатехином [ $\left.{ }^{10}\right]$, показывают, что продукты реакции имеют структуру, близкую к структуре исходного соединения, и что при дегра- 
Рис. 2. Изменение относительной оптической плотности при окислении кислородом воздуха $5 \cdot 10^{-5} \mathrm{M}$ водного раствора резорцина во времени при прямом колориметрическом определении: $I$ - с 4-аминоантипирином, II - с пирокатехином.

дации Р и 5MР в водном растворе, вероятно, происходит даль. нейшее гидроксилирование (о чем свиде тельствует повышение оптической плотности $>1,0)$, а также полимерообразование (практическое отсутствие снижения относительной оптической плотности во времени). Полимеры выделены также на линии старта при TCX.

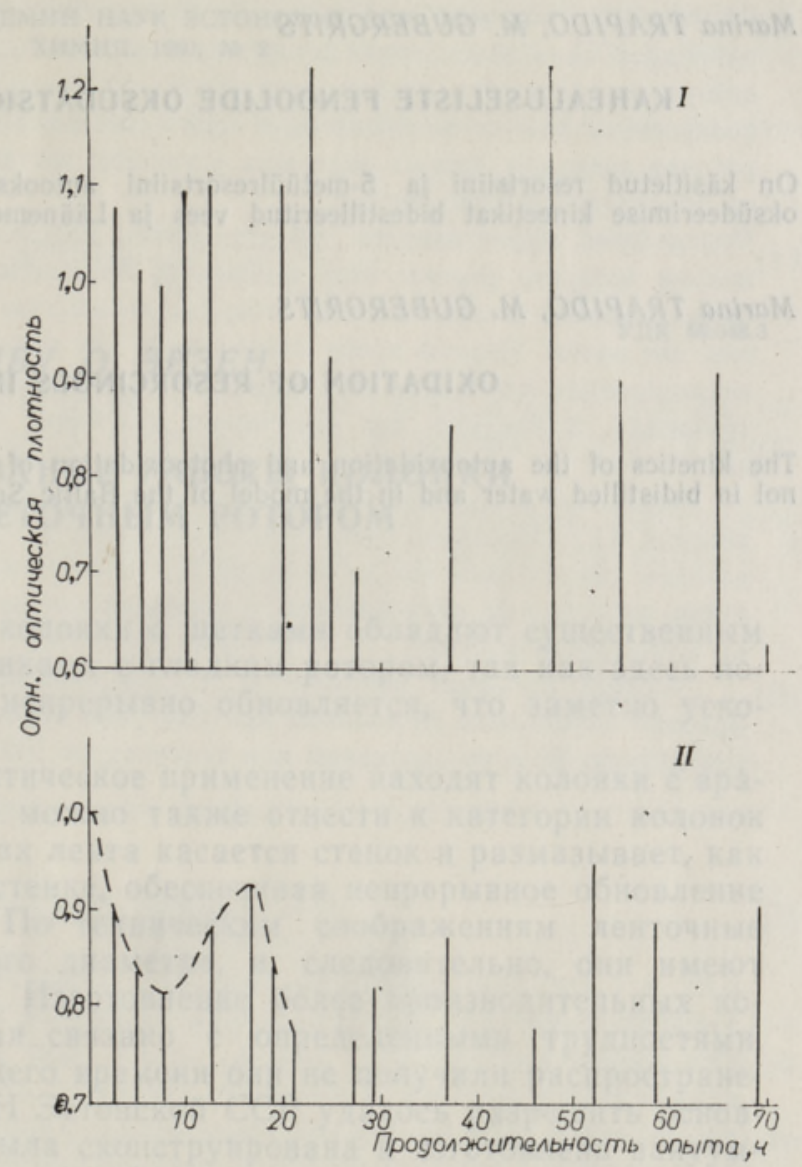

ЛИТЕРАТУ РА

1. С имонов А. И. Процессы самоочищения морских вод от химических загрязнений. - Тр. гос. океаногр. ин-та, 1978 , вып. 128 , с. 70.

2. Гу бергриц М. Я., Кирсо У. Э., Па а льме Л. П. Превращения канцерогенных веществ в биосфере. М., 1975.

3. Вредные вещества в промышленности, т. 2. М., 1976.

4. Thielemann, H. Zur Identifizierung und semiquantitativen dünnschichtchromatographischen Bestimmung von 1,4-Benzochinon in Abwässern der kohleverarbeitenden Industrie. - Z Z ges. Hyg., 1976, Bd. 22, N 3, S. 176-178.

5. Muss o, H. Ober Phenol-Oxydationen. - Angew. Chemie, 1963, Bd. 75, N 20, S. $965-977$.

6. Т рапи д о М. А., Ку й в К. А. Методика определения двухатомных фенолов в природных водах. - Горючие сланщы, 1976, № 11, с. 9-13.

7. Справочник химика, т. 5. М., 1968, с. 22.

8. Л ейд ле р К. Кинетика органических реакций. М., 1966.

9. Гордон А., Форд Р. Спутник химика. М., 1976, с. 519-523.

10. Лурье Ю. Ю., Рыб ников а А. И. Химический анализ производственных сточных вод. М., 1974. 
Marina TRAPIDO, M. GUBERGRITS

\section{KAHEALUSELISTE FENOOLIDE OKSUDATSIOON VESILAHUSTES}

On käsitletud resortsiini ja 5-metüülresortsiini autooksüdatsiooni ja fotoinitsieeritud oksüdeerimise kineetikat bidestilleeritud vees ja Läänemere vee mudelsüsteemis.

Marina TRAPIDO, M. GUBERGRITS

\section{OXIDATION OF RESORCINOLS IN WATER}

The kinetics of the autooxidation and photooxidation of resorcinol and 5-methylresorcinol in bidistilled water and in the model of the Baltic Sea water has been studied. 